\title{
Safety of percutaneous tracheostomy in patients with stroke
}

\author{
A Gritsan 1*, N Dovbish², G Gritsan³, A Gazenkampf ${ }^{4}$ \\ From ESICM LIVES 2015 \\ Berlin, Germany. 3-7 October 2015
}

\section{Introduction}

Percutaneous tracheostomy operation during prolonged mechanical ventilation is widely used in intensive care units for airway.

\section{Objectives}

To evaluate the safety of percutaneous tracheostomy versus surgical tracheostomy in patients with stroke.

\section{Methods}

Were examined 2 groups of patients with stroke who underwent tracheostomy overlay. In group 1 (68 patients) included patients who underwent percutaneous dilated tracheostomy imposed, in group 2 (65 patients) - which has been imposed surgical tracheostomy. The conditions for inclusion was the lack of lifethreatening dislocation syndrome associated with cerebral edema. Imposition of percutaneous tracheostomy was considered impossible in poor expression of anatomical landmarks (most often associated with obesity patients). Dilated tracheostomy superimposed using sets Rüsh or Portex. Endoscopic percutaneous tracheostomy support overlay was performed in 7 patients $(10.3 \%)$ in the presence of partial difficulties in determining the anatomical landmarks. The severity of the condition and the severity of neurological deficit at the time of imposition of tracheostomy was in group 1 were respectively: SOFA $3,5 \pm 1,8$ points, CGS $10,0 \pm$ 3,0 points in group 2: SOFA - 3,6 $\pm 1,8$ points, CGS $10,0 \pm 3,0$ points (no statistically significant difference). Were analyzed early complications and outcome indicators such as intensive care mortality and outcome of coma, estimated by CGO.

\section{Results}

Early complicationsare presented in Table 1 .

Table 1. Complications

\begin{tabular}{lllll}
\hline Complication & $\mathbf{1}$ group (68 patients) & $\mathbf{2}$ group (65 patients) & $\boldsymbol{\chi 2}$ \\
\hline Life threating & Death, Circulatory arrest, Pneumothorax, Pneumomediastinum & 0 & 0 & $0,007, p>0,05$ \\
\hline Severe & & $6(8.8 \%)$ & $6(9.2 \%)$ & $0,001, p>0,05$ \\
\hline & Desaturation & $1(1.5 \%)$ & $1(1.5 \%)$ & $0,173, p>0,05$ \\
\hline & Hypotension & $4(5.9 \%)$ & $5(7.7 \%)$ & 0 \\
\hline & Damage to the posterior tracheal wall & 0 & 0 & $0,962, p>0,05$ \\
\hline & Dislocation of the tube & $1(1.5 \%)$ & 0 & $0,389, p>0,05$ \\
\hline Mild & Aspiration, Bleeding & 0 & $1(3.1 \%)$ & \\
\hline & Difficultiesin setting & $1(1.5 \%)$ & & \\
\hline
\end{tabular}


Mortality in gr oup 1 was $50.0 \%$ in group $2-53,8 \%(\chi 2$ $0,197, \mathrm{p}>0.05)$. SGO outcomes for whom made in group $11,8 \pm 1,1$,in group $2-1,8 \pm 1,9$.

\section{Conclusions}

The imposition of percutaneous dilated tracheostomy in selected group of patients with stroke is a safe way tracheostomy, the incidence of complicationsis not different from the group of surgical tracheostomy. Long-term results also do not differ between the groups of patients.

\section{Authors' details}

${ }^{1}$ Krasnoyarsk State Medical University, Krasnoyarsk Regional Clinical Hospital, Anaesthesiology and Intensive Care 5, Krasnoyarsk, Russian Federation. ${ }^{2}$ Krasnoyarsk Regional Clinical Hospital, Anaesthesiology and Intensive Care 5, Krasnoyarsk, Russian Federation. ${ }^{3}$ Krasnoyarsk State Medical University, Anaesthesiology and Intensive Care, Krasnoyarsk, Russian Federation. ${ }^{4}$ Krasnoyarsk State Medical University, Krasnoyarsk Regional Hospital, Anaesthesiology and Intensive Care 5, Krasnoyarsk, Russian Federation.

Published: 1 October 2015

doi:10.1186/2197-425X-3-S1-A778

Cite this article as: Gritsan et al:: Safety of percutaneous tracheostomy in patients with stroke. Intensive Care Medicine Experimental 2015 3(Suppl 1):A778.

\section{Submit your manuscript to a SpringerOpen ${ }^{\odot}$ journal and benefit from:}

- Convenient online submission

- Rigorous peer review

- Immediate publication on acceptance

- Open access: articles freely available online

- High visibility within the field

- Retaining the copyright to your article 